
WITH AUTOIMMUNE RHEUMATIC DISEASES: AN ITALIAN RHEUMATOLOGISTS' SURVEY

F. R. Spinelli ${ }^{1}$, F. Cacciapaglia ${ }^{2}$, F. Atzeni ${ }^{3}$, G. Erre ${ }^{4}$, A. Manfredi ${ }^{5}$, E. Bartoloni Bocci $^{6}$, M. Piga ${ }^{7}$, G. Sakellariou ${ }^{8}$, O. Viapiana ${ }^{9}$, E. Gremese ${ }^{10,11} .{ }^{1}$ Sapienza Università di Roma, Rheumatology Unit, Rome, Italy; ${ }^{2}$ Azienda Ospedaliero Universitaria Policlinico di Bari, Reumatology Unit, Bari, Italy; ${ }^{3}$ Azienda Ospedaliera Universitaria Policlinico Gaetano Martino, Rheumatology Unit, Messina, Italy; ${ }^{4}$ Azienda Ospedaliera Universitaria Sassari, Rheumatology Unit, Sassari, Italy; ${ }^{5}$ Policlinico di Modena, Rheumatology Unit, Modena, Italy; ${ }^{6}$ Università degli studi di Perugia, Rheumatology Unit, Perugia, Italy; ${ }^{7}$ Università di Cagliari, Rheumatology Unit, Cagliari, Italy; ${ }^{8}$ Università degli studi di Pavia, Rheumatology Unit, Pavia, Italy; ${ }^{9}$ Universita degli studi di Verona, Rheumatology Unit, Verona, Italy; ${ }^{10}$ Università Cattolica del Sacro Cuore, Rheumatology Unit, Rome, Italy; ${ }^{11}$ Fondazione Policlinico Universitario A. Gemelli IRCCS, Rheumatology Division, Rome, Italy

Background: Cardiovascular (CV) disease is the leading cause of morbidity and mortality in patients with inflammatory arthritis. The growing attention to the CV risk characterizing patients with autoimmune inflammatory disease led EULAR to provide recommendations on $\mathrm{CV}$ risk management (1). To date, there are no data on the adherence to EULAR recommendation among Italian rheumatologists. Objectives: Our objective was to measure the level of awareness and the attitude to manage $\mathrm{CV}$ risk.

Methods: Italian rheumatologists were invited to anonymously answer a web-based questionnaire designed by the steering committee of the Cardiovascualr and Obesity in Rheumatic Diseases (CORDIS) study group of the Italian Society of Rheumatology. The first part of the questionnaire concerned demographic information; the subsequent questions concerned the attitude to assess $\mathrm{CV}$ risk and the limitations for not assessing, the specific $\mathrm{CV}$ risks considered in the clinical practice and their management. Data are presented using standard summary statistics and were expressed as mean+/-standard deviation or median (interquartile range) according to variables' distribution. Results: One thousand-three hundred rheumatologists (of whom 500 are under 40 and 100 over 70 years of age) have been invited by email to complete the survey. The questionnaire has been filled by 102 rheumatologists $(7.85 \%)(53$ females and 49 males) with a median age of 38 years (32-48) and a median of $4(0-15)$ years of specialization. Most of the physician who answered the questionnaire works in University Hospitals (67/102; 65.7\%), 22 out of $102(21.6 \%)$ in non-academic Hospitals, and the remaining $12,7 \%$ in territorial outpatient clinics.

When asked if they usually evaluate $\mathrm{CV}$ risk in patients with autoimmune rheumatic diseases, 67/102 (67.2\%) answered positively, 18 no (17.6\%) and 7 did not answer the question; $82 \%$ of those who routinely assess the CV do it by themselves. The barriers limiting the assessment of CV risk included: i) lack of time (79\%); ii) complex management (12\%); inadequate training (9\%).

As for the CV risk factors, lipid profile, hypertension and diabetes are assessed by most of the rheumatologists $(90 \%, 89 \%$ and $88 \%$, respectively), family history by $78 \%$ and body mass index by $75.3 \%$ and waist circumference only by $25 \%$ of those who completed the survey.

Finally, only $18.6 \%$ stated that they manage by themselves $\mathrm{CV}$ risk in patients with autoimmune rheumatic diseases while $50 \%$ refer patients to other specialists and $23.4 \%$ to general practitioner.

Conclusion: Despite the growing awareness on the CV risk characterizing patients with autoimmune rheumatic disease, about one third of young Italian rheumatologists does not strictly adhere to the EULAR recommendations on $\mathrm{CV}$ management, mostly due to insufficient time during the routine care visits.

References:

[1] Agca R et al. Ann Rheum Dis 2017; 76: 17-28

Disclosure of Interests: Francesca Romana Spinelli Grant/research support from: Pfizer, Speakers bureau: Lilly, BMS, Celgene, Fabio Cacciapaglia Speakers bureau: BMS; Roche; Pfizer; Abbvie, Fabiola Atzeni: None declared, Gianluca Erre: None declared, Andreina Manfredi: None declared, Elena Bartoloni Bocci: None declared, Matteo Piga: None declared, Garifallia Sakellariou Speakers bureau: Abbvie, Novartis, MSD, Ombretta Viapiana: None declared, Elisa Gremese Speakers bureau: Abbvie, BMS, Celgene, Jannsen, Lilly, MSD, Novartis, Pfizer, Sandoz, UCB

DOI: 10.1136/annrheumdis-2020-eular.6093

\section{SAT0093 CDAI AND DAS28 IN THE MANAGEMENT OF RHEUMATOID ARTHRITIS IN CLINICAL PRACTICE}

S. Takanashi ${ }^{1}$, Y. Kaneko ${ }^{1}$, T. Takeuchi ${ }^{1}{ }^{1}$ Keio University School of Medicine, Division of Rheumatology, Department of Internal Medicine, Tokyo, Japan

Background: The primary therapeutic target for rheumatoid arthritis (RA) is remission, assessed using validated composited measures. Currently, indexbased remission frequently used in clinical practice are disease activity (CDAI) and disease activity score for 28 joints (DAS28). Generally, CDAl is believed more stringent than DAS28 in assessing clinical remission, however, this confirmation was mainly derived from trial results.

Objectives: To investigate the real-world performance of CDAI and DAS28 -erythrocyte sedimentation rate (ESR) in RA.

Methods: We reviewed consecutive RA patients who are receiving any disease modifying anti-rheumatic drug (DMARDs) in Keio University Hospital between 2016 and 2017 and collected medical information. We focused on the patients in CDAI remission and/or DAS28-ESR remission at the time of last visit, and analyzed their clinical characteristics.

Results: A total of 1585 patients with RA were reviewed. Their characteristics were mean age of 64 years old, female of $84 \%$ and mean disease duration of 12.0 years. Current treatments were conventional synthetic (cs) DMARDs alone, TNF inhibitors (TNFi), IL-6 receptor inhibitors (IL-6i), CTLA-4Ig, and JAK inhibitors (JAKi) in $39.2 \%, 29.0 \%, 22.8 \%, 7.1 \%$, and $1.8 \%$ patients, respectively. Of them, $62.7 \%$ were in CDAl remission and $64 \%$ were in DAS28-ESR remission. Among patients in CDAI remission, the proportion of DAS28-ESR non-remission was $19.4 \%$ in those treated with csDMARDs, $18.2 \%$ treated with TNFi, $4.2 \%$ treated with IL-6i, $27.6 \%$ treated with CTLA-4Ig, and $33.3 \%$ treated with JAKi (Figure). In contrast, among patients in DAS28 remission, the proportion of CDAl non-remission was $11.7 \%$ in those treated with csDMARDs, $15.4 \%$ treated with TNFi, $29.5 \%$ treated with IL-6i, $16.0 \%$ treated with CTLA-4Ig, and $14.3 \%$ treated with JAKi. Venn diagrams of CDAI remission and DAS28-ESR remission demonstrated that more patients satisfied the CDAI remission criteria without satisfying the DAS28-ESR remission criteria than vice versa, except for those treated with IL-6i (Figure). Patients in CDAI remission and DAS28-ESR non-remission had higher $\mathrm{C}$-reactive protein, ESR and comorbidity rates $(0.37$ vs $0.07 \mathrm{mg} / \mathrm{dL}, \mathrm{p}<0.001 ; 45.7$ vs $8.0 \mathrm{~mm} / \mathrm{h}, \mathrm{p}<0.001 ; 26.4$ vs $18.0 \%, p=0.07$ respectively), and those in CDAI non-remission and DAS28-ESR remission had worse patient-reported outcomes including patient global assessment and health assessment questionnaire-disability index $(31.1 \mathrm{vs} 9.5 \mathrm{~mm}, p<0.001$ 0.82 vs $0.41, p<0.001$, respectively). Patients in both CDAI and DAS28-ESR remission were apparently in better disease activity than those who met either criteria.

Conclusion: Assessing patients with two composite measures simultaneously is important to evaluate patients' condition from view points of RA itself and comorbidities and adjust treatment appropriately.

\section{References:}

[1] Smolen JS et al. T2T Expert Committee. Treating rheumatoid arthritis to target: recommendations of an international task force. Ann Rheum Dis. 2010;69(4):631-7.
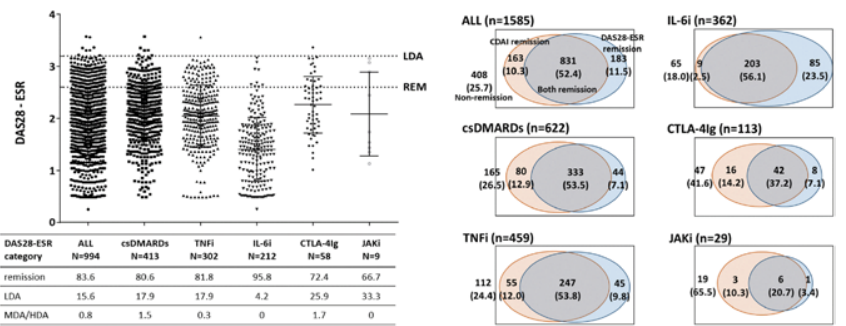

Disclosure of Interests: Satoshi Takanashi: None declared, Yuko Kaneko Speakers bureau: Dr. Kaneko reports personal fees from AbbVie, persona fees from Astellas, personal fees from Ayumi, personal fees from Bristol-Myers Squibb, personal fees from Chugai, personal fees from Eisai, personal fees from Eli Lilly, personal fees from Hisamitsu, personal fees from Jansen, personal fees from Kissei, personal fees from Pfizer, personal fees from Sanofi, personal fees from Takeda, personal fees from Tanabe-Mitsubishi, personal fees from UCB, Tsutomu Takeuchi Grant/research support from Eisai Co., Ltd, Astellas Pharma Inc., AbbVie GK, Asahi Kasei Pharma Corporation, Nippon Kayaku Co., Ltd, Takeda Pharmaceutical Company Ltd, UCB Pharma, Shionogi \& Co., Ltd., Mitsubishi-Tanabe Pharma Corp., Daiichi Sankyo Co., Ltd., Chugai Pharmaceutical Co. Ltd., Consultant of: Chugai Pharmaceutical Co Ltd, Astellas Pharma Inc., Eli Lilly Japan KK Speakers bureau: AbbVie GK, Eisai Co., Ltd, Mitsubishi-Tanabe Pharma Corporation, Chugai Pharmaceutical Co Ltd, Bristol-Myers Squibb Company, AYUMI Pharmaceutical Corp., Eisai Co., Ltd, Daiichi Sankyo Co., Ltd., Gilead Sciences, Inc., Novartis Pharma K.K., Pfizer Japan Inc., Sanofi K.K., Dainippon Sumitomo Co., Ltd. DOI: 10.1136/annrheumdis-2020-eular.1377

\section{SAT0094 \\ ASSESMENT OF BONE MINERAL DENSITY AND FRACTURE RISK IN PATIENTS WITH RHEUMATOID ARTHRITIS AND SARCOPENIA}

O. Dobrovolskaya ${ }^{1}$, Z. Kolkhidova ${ }^{1}$, A. Menshikova ${ }^{1}$, N. Demin ${ }^{1}$, N. Toroptsova ${ }^{1}$. ${ }^{1}$ V.A. Nasonova Scientific and Research Institute of Rheumatology, Moscow, Russian Federation 